\title{
Risk management perspective for climate service development - Results from a study on Finnish organizations
}

\author{
Atte Harjanne $^{1,2}$, Riina Haavisto ${ }^{1}$, Heikki Tuomenvirta ${ }^{1}$, and Hilppa Gregow ${ }^{1}$ \\ ${ }^{1}$ Finnish Meteorological Institute, Erik Palménin aukio 1, 00560 Helsinki, Finland \\ ${ }^{2}$ Aalto University School of Business, Runeberginkatu 14-16, 00100 Helsinki, Finland
}

Correspondence to: Atte Harjanne (atte.harjanne@fmi.fi)

Received: 13 January 2017 - Revised: 6 September 2017 - Accepted: 11 September 2017 - Published: 11 October 2017

\begin{abstract}
Weather, climate and climate change can cause significant risks to businesses and public administration. However, understanding these processes can also create opportunities. Information can help to manage these risks and opportunities, but in order to do so, it must be in line with how risk management and decision making works. To better understand how climate risks and opportunities are reflected in different organizational processes and what types of information is needed and used, we conducted a study on the perceptions and management of weather and climate risks in Finnish organizations and on their use of weather and climate information. In addition, we collected feedback on how the existing climate information tools should be developed.

Data on climate risk management was collected in an online survey and in one full-day workshop. The survey was aimed to the Finnish public and private organizations who use weather and climate data and altogether 118 responses were collected. The workshop consisted of two parts: weather and climate risk management processes in general and the development of the current information tools to further address user needs.

We found that climate risk management in organizations is quite diverse and often de-centralized and that external experts are considered the most useful sources of information. Consequently, users emphasize the need for networks of expertise and sector-specific information tools. Creating such services requires input and information sharing from the user side as well. Better temporal and spatial accuracy is naturally asked for, but users also stressed the need for transparency when it comes to communicating uncertainties, and the availability and up-to-datedness of information.

Our results illustrate that weather and climate risks compete and blend in with other risks and changes perceived by the organizations and supporting information is sought from different types of sources. Thus the design and evaluation of climate services should take into account the context of existing and developing processes in organizational risk management.
\end{abstract}

1

Introduction

Even as our understanding of climatic processes and their impacts is steadily improving, fundamental uncertainties in climate and its impacts remain. Adapting to current and future climate is thus essentially risk management. It should be noted, though, that a broad view of risk management does not only include reducing losses and damages but also seizing opportunities. Climate services are in this sense tools for managing climate risks. For clarity, we define climate risks here as risks caused by weather, climate and climate change.

The use and usefulness of different climate information and climate services have been discussed in many papers and studies of different scale and scope. Lemos et al. (2012) pointed out the usability gap between needed and provided information. The insufficiencies of the traditional provision of climate information have also been brought up in various studies looking at information products, such as seasonal forecasts (Bolson et al., 2013; Kirchhoff et al., 2013; Soares 
and Dessai, 2016) and scenario-based climate predictions (see e.g. Kirchhoff et al., 2013; Pilli-Sihvola et al., 2014; Soares and Dessai, 2016). Typically deeper co-operation with suppliers and users and demand- or user-driven approaches (McNie, 2013; Lourenço et al., 2015; McGregor, 2015) are suggested as measures to address these challenges of the production and use of climate information.

Surveying user needs and tailoring services accordingly might very well result in improved adaptation. But it might also be too narrow of an approach because not all potential users or stakeholders are able to articulate their needs. In order to reach a wider audience, it might be wise to take a more in-depth view and try to understand especially the organizational context for the use of climate information. Following suggestions by Berkhout (2012), Kirchhoff et al. (2013) and Vaughan and Dessai (2014) to evaluate climate services in an organizational context we take a step back and look at the fundamentals in current use and needs for climate information in Finnish organizations. In this condensed paper we focus on the interpretation and conclusions of the results and discuss them in the context of organizational risk management. Since weather and climate are sources of different risks to organizations, this risk management perspective can bring valuable new insights to climate services development.

The research described here was conducted as a part of a research project Proactive management of weather and climate related risks (ELASTINEN) that was funded by the Prime Minister's Office of Finland within the Government's analysis, assessment and research activities. The results described here have previously been discussed in separate reports (in Finnish) (Harjanne et al., 2016; Gregow et al., 2016).

\section{Study design}

The study was based on two consecutive methods. First, a survey was prepared for Finnish public and private organizations. The survey questionnaire covered background information, the impacts of weather and climate to the organization including risk management practices relating to weather and climate, information sources and their usefulness, and the improvement/development of preparedness. The survey respondents were sampled from existing stakeholder lists maintained by the partners within the study. Of the 500 recipients 118 responded to study. The survey was conducted using an online form and the responses were collected between 30 November and 13 December 2015 during which time two reminder messages were sent. The survey study was designed to be explorative in nature and the final recipient sample is not a statistical representation of the Finnish organizations in general. The English translation of the full survey questionnaire is presented in Appendix A, and in the results section specific questions are referred by their number in parentheses.
The survey was followed by a stakeholder workshop held at the premises of the Finnish Meteorological Institute on 27 January 2016. The workshop brought together 42 experts from different stakeholder organizations with the aim of deepening the survey results and further developing ideas on the management of weather and climate risks both in general terms and regarding specific information services. The workshop participants were invited using the same pool of recipients that was used in the survey, with the idea to collect more in depth views on the issues touched upon in the survey. The combined results from the survey and the workshop were then analysed in the context of risk management, with the aim of synthesizing pragmatic conclusions and guidelines to support the future provision of climate services and climate related decision making.

\section{Results}

\subsection{Survey results}

The survey respondents represented a wide spectrum of different organizations within Finland. A little over half $(53.5 \%)$ were public organizations, $37.7 \%$ represented private enterprises, and the remaining $8.7 \%$ were non-profit organizations (Question \#1). Different sectors were varyingly represented with the largest shares by agriculture and food production (15\%) and health services (12\%) (Question \#2). The individuals representing the respondent organizations were experts $(40.4 \%)$, executives $(36.8 \%)$ and middle management (22.8\%) (Question \#7), and a clear majority ( $87 \%)$ had over 5 years of expertise in working in their field (Question \#9). The survey had altogether 31 questions that covered weather and climate risk management from various aspects.

Regarding the impacts of weather and climate to the respondents, heavy rain, flooding and storm winds were considered the most harmful phenomena affecting them (Question \#14). When categorizing different types of phenomena, extreme events were considered more significant than permanent climatic shifts which were then more significant than exceptional seasonal conditions, as depicted in Table 1 (Question \#10). In general, the events in Finland were considered more significant than those occurring outside Finland, hinting that direct impacts are a more significant cause for concern than indirect ones.

Overall, a little over half (54\%) of the respondents considered weather and climate risks either as more significant than or at least as significant as other risks in general (Question \#22). When asked about the potential positive impacts of climate change, (Question \#12) $48 \%$ of the respondents identified some positive impacts or future opportunities such as enabling new business or improving market position in relation to others as presented in Fig. 1. 
Table 1. Significance of different types of climatic phenomena to the respondent organizations (Appendix A, Question \#10).

\begin{tabular}{lr}
\hline Type of phenomena & $\begin{array}{r}\text { Significance } \\
\text { Currently observed extreme weather events in Finland }\end{array}$ \\
\hline Currently observed extreme weather events abroad & 3.84 \\
More severe or new types of extreme weather events in Finland & 2.62 \\
More severe or new types of extreme weather events abroad & 3.92 \\
Long lasting exceptional seasonal conditions in Finland & 2.84 \\
Long lasting exceptional seasonal conditions abroad & 3.59 \\
Permanent shifts in average climate in Finland & 2.71 \\
Permanent shifts in average climate abroad & 3.61 \\
\hline
\end{tabular}

Avoiding economic losses was the principal driver of weather and climate risk management especially in the private sector (Question \#18). Almost all of the responding organizations have assessed their weather and climate risks however only $36 \%$ do this systematically and not only sporadically or through a one-time effort (Question \#15). Figure 2 provides a more detailed breakdown.

The assignment of responsibility for managing weather and climate risks was diverse across the respondent organizations (Question \#17). While around half (51\%) had a designated person responsible for managing weather and climate risks, the organizational function of this person varied greatly between the respondents. Most typical functions were risk management, production or corporate responsibility and environmental management. $40 \%$ have not assigned a clear responsibility over weather and climate risks and the remaining $9 \%$ of respondents did not know the situation. Considering time scales within risk management, organizations that expand their risk horizons over 10 years in the future were a minority (15\%) among the respondents (Question \#16).

Regarding information sources, the networks of internal and external experts, open data and specific information products were in general considered most useful in managing weather and climate risks (Question \#25). The detailed results are presented in Table 2. As for the barriers resulting from the information itself, the usefulness of information is limited by the limitations in temporal and spatial resolution and uncertainty (average significance of 3.4 on a five-scale evaluation, Question \#34). Limits of available and accessible information were also considered among the most significant barriers to weather and climate risk management (average significance 3.0) together with lack of resources within the respondent organizations (average significance 3.1). Rest of the suggested barriers were on average considered less than somewhat significant as they scored less than 3.0 on the scale. These barriers could likely be most efficiently addressed with tailored and more usable information and transparent communication of uncertainty such as including probabilities in predictions and forecasts, as these measures scored high in the follow-up question (Question \#30). Establishing expert networks and assembling information from different sources into one-stop portals were also considered significant possibilities to improve preparedness and weather and climate risk management.

\subsection{Workshop results}

The discussions in the workshop followed similar lines to the survey results. In general, the main outcomes of the discussions can be grouped under six themes:

- Improving communication

- Actionable predictions and warnings

- Sector-specific perspectives

- Expert networks

- Business opportunities

- Regional adaptation

Regarding improvements in communication, the participants brought up that information on weather and climate risks needs to be easily and timely accessible and understandable. Visualizations, practical approach and storytelling are potential ways to freshen up communication and increase interest. Crowdsourcing and social media platforms may enable reaching new audiences.

The workshop participants also concluded that actionable predictions and warnings would require not only more precision and accuracy but also designing services from the user perspective. This could mean including impact information as well as assessments of uncertainties and return periods within the predictions. Participants also considered transparency in the form of frequent updating and communication of different probabilities (i.e. not only the most likely impacts but also the likelihood of the most severe impacts) important in connecting weather and climate information to decision making.

The participants representing different sectors and industries commented that sector-specific perspectives are required since the risk profiles and connections between weather and climate and the operations are very different in 


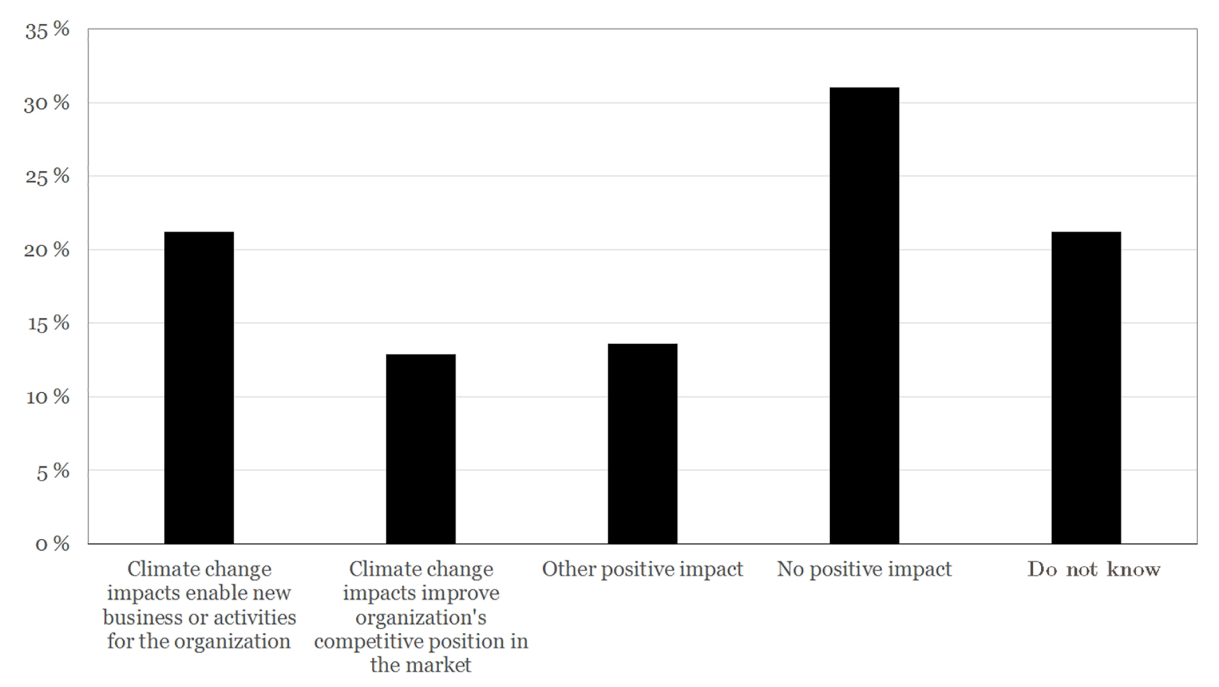

Figure 1. The respondents' view on the question "Does climate change result in beneficial impacts to your organization?" (Appendix A, Question \#12).

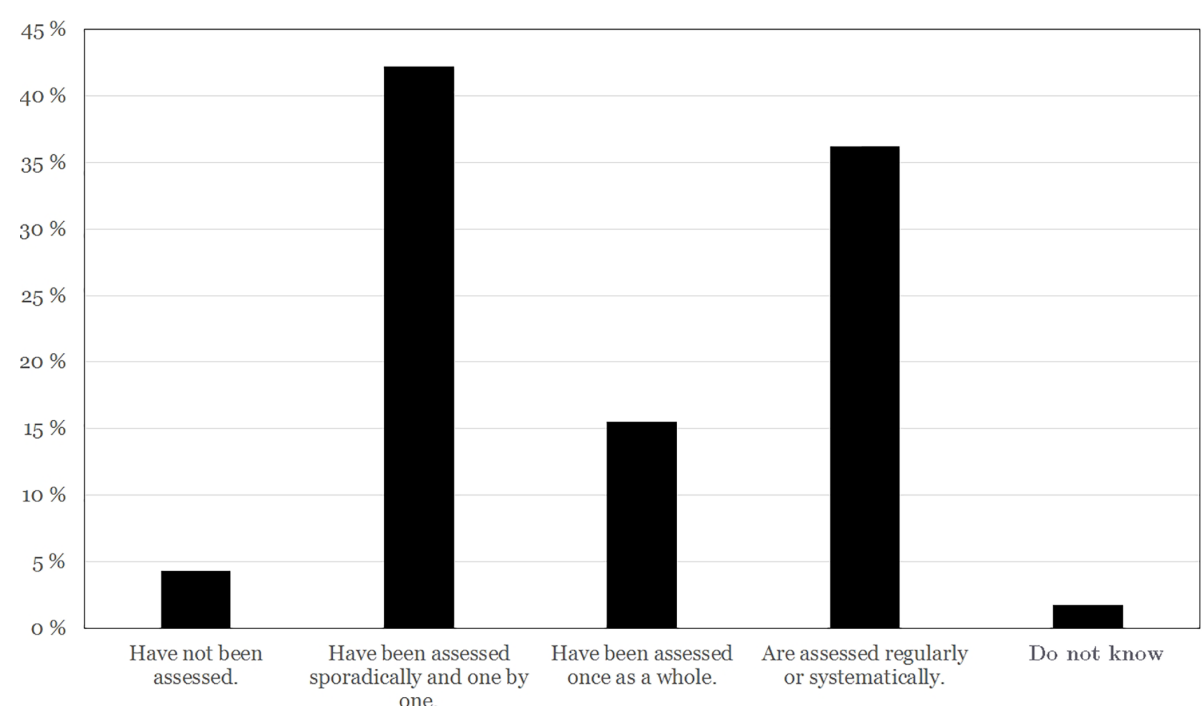

Figure 2. The respondents' view on question: "How has your organization assessed current and expected weather and climate risks?" (Appendix A, Question \#15).

different lines of business. Many sectors would benefit from stepwise warnings instead of the now typically used binary threshold where there either is or isn't a warning. Another beneficial development would be predictions that describe impacts on critical infrastructures or key functions within society.

The benefits of expert networks were already shown in the survey and were continued to be emphasized by the participants within the workshop. Internal and external experts are considered important sources of information, and information and experiences from peers have a major role in adopting weather and climate risk related knowledge. According to the participants, it would be important to establish perma- nent bodies and continuous practices of co-operation instead of launching one project after another and there is a need both for sector-specific networks and co-operation across sectors. Industry associations were suggested as especially fitting for distributing knowledge and maintaining contact between weather and climate service providers and users.

According to the workshop discussions, strong emphasis on the negative consequences of weather and climate may hinder the recognition of business opportunities that successful management of the risks can create. The participants believed that creating products and services to manage climate risks or seize opportunities has large potential markets internationally. The public sector can enable such market cre- 
Table 2. The respondents' views on the usefulness of different information sources in managing weather and climate risks (Appendix A, Question \#25).

\begin{tabular}{|c|c|c|}
\hline Source of information & $\begin{array}{r}\text { Usefulness } \\
(5=\text { extremely } \\
\text { useful } \ldots 1=\text { useless })\end{array}$ & $\begin{array}{r}\text { Number of respondents } \\
\text { considering source } \\
\text { as "detrimental" }\end{array}$ \\
\hline Contacts with external experts & 4.12 & - \\
\hline Open climate and weather data & 3.97 & - \\
\hline Internal experts & 3.8 & - \\
\hline Professional literature and expert reports & 3.7 & - \\
\hline Industry networks and organizations & 3.68 & - \\
\hline Tools illustrating climate change and its impacts (interactive flood maps etc.) & 3.68 & - \\
\hline Online portals on weather and climate issues & 3.63 & - \\
\hline Scientific publications & 3.57 & - \\
\hline Stakeholder feedback (surveys, interviews, workshops, public events) & 3.47 & - \\
\hline Public spatial datasets & 3.42 & - \\
\hline Standards and guidelines & 3.36 & - \\
\hline Traditional media & 3.15 & - \\
\hline Historical material (e.g. traditional knowledge, photos, maps) & 3.04 & - \\
\hline Consultants & 2.96 & 2 \\
\hline Social media & 2.59 & 5 \\
\hline
\end{tabular}

ation by implementing encouraging regulation and tendering processes. Regulation could, for example, promote integrated risk assessments that include climate risk considerations. The public sector could also proactively procure innovative climate risk management tools.

Regional adaptation was brought up in the workshop as an important perspective since both weather and climate risks and resources to manage these risks vary largely between regions in Finland. This was considered especially true for the public sector, as municipalities have the main responsibility for adaptation activities but are in many cases small and lack funding and expertise. In the face of these challenges investments in regional co-operation would be justified. The forms of this type of co-operation were not detailed in the workshop but in the case of Finland the existing provincial institutions could be suitable to become the aggregators and distributors of regionally relevant adaptation expertise. Currently provinces have a very limited jurisdictional role, but the plan is to change this in a regional reform that takes place in 2020 .

\section{Discussion}

As presented above, climate risk management can be considered as one aspect of organizational risk management in general, and risk management itself is nothing new to most organizations, be they public or private. How should climate services then be designed and evaluated from the perspective of risk management within organizations? Some conclusions can be drawn based on the above described results as well as from earlier literature.
The results of both the survey and the workshop revolve largely around two broad issues: communication and cooperation. Improving these is clearly the path forward, but it may not be as straightforward as it seems. These are not exactly novel ideas, yet they still come up whenever these issues are discussed. Contextualizing climate services within existing organizational risk management schemes might then offer a practical way of realizing the potential of climate information in adaptation.

With such a small-scale study, the results are only indicative but some relevant aspects can be inferred. First of all, weather and climate risks might not constitute a distinguishable or especially significant category of risks for many users. The management of weather and climate risks is largely driven by their economic implications and the management is spread across different functions and processes. This can be because weather and the changing climate pose very different types of risks and opportunities depending on the sector, time horizon, the line of business, and general perspective. Thus weather and climate risk management is also inherently interdisciplinary and requires combining different types of data, information, and expertise.

Similar findings have been proposed in previous literature. Lash and Wellington (2007) discussed the broadness and variety of climate risk to businesses by distinguishing six types of risks resulting from climate change: regulatory risks, supply chain risks, product and technology risks, litigation risks, reputational risks, and physical risks. Berkhout (2012) pointed out that only few actions in organizations are responses to climate impacts alone - changes are also shaped by drivers, such as technology and strategy. And if climate issues are dealt within a distinct business response, the lines 
between adaptation to and mitigation of climate change seem to blur (Linnenluecke et al., 2013). Regarding economic impacts, the challenge within risk management in businesses is quantifying uncertainty, which in the case of changing climate is inherently complex (Winn et al., 2011).

Our results indicate some challenges in developing climate services. The diverse and dispersed nature on how and by whom climate risks are managed in organizations is a challenge for communicating the potential of climate services to potential users. It also makes it more difficult to form the expert networks that were considered as an important source for information. This may mean that close cooperation can become arduous; such collaboration requires time and effort. Thus developing effective and efficient climate services requires acknowledging that utilizing their potential also requires resources and capacity from the user side. Currently, the lack of resources can be an obstacle. Boundary organizations (see e.g. Guston, 1999; Hoppe and Wesselink, 2014) could be one way to address this issue by mediating the demand and supply of climate services. Developing shared vocabulary and contextualizing climate information are probably necessary steps in the path towards more climate ready society. Perhaps even the concept of climate services itself needs to be reconsidered, if it does not prove useful and engaging.

\section{Conclusions}

Adapting to changing climate is inherently a risk management process where actors seek ways to mitigate the negative impacts and seize opportunities brought and created by the change. Based on a survey and a workshop among Finnish organizations and on supporting literature, our study indicates that managing weather and climate risks is diverse and de-centralized. These risks compete and blend in with other risks and changes perceived by the organizations and information is sought from various different types of sources. Climate risk management typically does not form a distinct or separate category of actions or a specific process, and thus the design and evaluation of climate services should take into account this context of organizational risk management processes.

Looked at this way, climate services are essentially about risk management. Risk management in turn is about protecting and developing the organization's core business, be it public or private in nature. Supporting this core business then determines the value of climate services to an organization. Only if this is acknowledged and taken into account in service development can climate services live up to their potential.
Data availability. The survey data is available (in Finnish) in the Finnish Social Science Data Archive with the identification title "FSD3105 Weather and Climate Risk Management in Finnish Organisations 2015" (http://urn.fi/urn:nbn:fi:fsd:T-FSD3105, http: //www.fsd.uta.fi/en/, Gregow et al., 2015). 


\section{Appendix A: Survey questionnaire template}

1. Type of organization

a. Private company

b. Public entity, public utility company, municipal federation or publicly owned company

c. NGO

d. Other, what?

2. Industry sector

a. Planning of areas and land use

b. Energy production and distribution

c. Waste management

d. Commercial sector

e. Property management

f. Machinery production

g. Education

h. Cultural heritage and capital

i. Transportation and logistics

j. Agriculture and food production

k. Tourism

1. Metal industry

$m$. Forest industry

n. Services

o. Financing

p. Rescue services

q. Construction

r. Technical consulting

s. Health care

t. Science and research

u. Safety services

v. Water resource management

w. Public administration

$\mathrm{x}$. Environment and natural resource management

y. Other, what?

3. If you answered "Other, what", specify here the sector

4. Size of the organization

a. Micro-enterprise (below 10 persons) or other organization of the same size

b. SME (10-250 persons) or other organization of the same size

c. Large company (over 250 persons) or other organization of the same size
5. If organization is public, is it
a. Municipal, population $<5000$
b. Municipal, population 5000-10000
c. Municipal, population 10000-20000
d. Municipal, population 20000-50000
e. Municipal, population $>50000$
f. Regional
g. National

6. Principal area of operations
a. International
b. Whole Finland
c. Uusimaa
d. Varsinais-Suomi
e. Satakunta
f. Kanta-Häme
g. Pirkanmaa
h. Päijät-Häme
i. Kymenlaakso
j. South Karelia
k. Etelä-Savo
1. Pohjois-Savo
m. North Karelia
n. Central Finland
o. South Ostrobothnia
p. Ostrobothnia
q. Central Ostrobothnia
r. North Ostrobothnia
s. Kainuu
t. Lapland
u. Åland

7. What is your position within the organisation
a. Expert
b. Middle management
c. Senior management
d. Other, what?

8. Primary area of responsibility or job description
a. Sales and marketing
b. Risk management
c. Strategic planning
d. Health 

e. Property and security issues
f. Production or other operative activity
g. Research and development
h. Communications
i. Environment or corporate responsibility
j. Human resources
k. Administration
1. $\mathrm{CEO}$
m. Other, what?

9. Experience in years in the current sector
a. Below 1
b. $1-5$
c. $5-10$
d. $10-15$
e. Over 15

10. Assess the significance of different weather and climate phenomena for your organization's performance. (Very significant, significant, somewhat significant, somewhat meaningless, meaningless)

a. Current weather phenomena in Finland (e.g. heavy rainfall, storms, floods or heat waves)

b. Current weather extremes beyond Finland's borders (e.g. heavy rainfall, storms, floods or heat waves)

c. More intense or new types of weather phenomena in the future in Finland

d. More intense or new types of weather phenomena in the future beyond Finland's borders

e. Long lasting, exceptional seasonal conditions in Finland (e.g. warmer winter, long drought, lack of fungus or ice)

f. Long lasting, exceptional seasonal conditions beyond Finland's borders (e.g. warmer winter, long drought, lack of fungus or ice)

g. Persistent changes in the average climate in Finland (e.g. rising average temperature, rainfall change, ice and snow cover, changes in wind and cloud conditions)

h. Persistent changes in the average climate beyond Finland's borders (e.g. rising average temperature, rainfall change, ice and snow cover, changes in wind and cloud conditions)

11. Specify your answers, if necessary:

12. Does climate change result in beneficial impacts to your organization? a. The impacts of climate change will allow us new activities or business

b. Impact of climate change will improve our relative position in the market

c. Other benefit, please specify:

d. No

e. I don't know

13. Specify your answers, if necessary:

14. What are the most significant adverse weather phenomena for your organization?
a. Heavy rains
b. Floods
c. Storm winds
d. Lightning
e. (Prolonged) drought
f. Heat wave
g. Relatively high temperature for the season
h. Relatively low temperature for the season
i. Extremely low temperature
j. Hail
k. Large amount of snow or heavy snow
1. Lack of snow
m. Freezing rain
n. Ground frost
o. Lack of ground frost
p. Other, what?

15. How has your organization assessed current and expected weather and climate risks?

a. Risks have not been assessed at all

b. Risks have been assessed randomly and individually

c. Risks have been assessed one-off as a whole

d. Risks are assessed regularly

e. I don't know

16. In what time frame do you assess the risks to your organization?
a. Below 5 years
b. 5-10 years
c. 10-20 years
d. Over 20 years
e. Over 50 years 
17. Who is responsible for managing weather and climate risks in your organization?

a. Corporate or Environmental Manager or equivalent

b. Risk Manager or equivalent

c. Technology Manager or equivalent

d. Safety Manager or equivalent

e. Production Manager or equivalent

f. CEO

g. Other, who?

h. The management of weather and climatic risks is not specifically assigned for anyone in our organization

i. I don't know

18. What are the two most important drivers of weather and climate risk management in your organization? (Primary driver)
a. Avoiding economic losses
b. Work safety
c. Process safety
d. Environmental safety
e. Health protection
f. Responsibility and reputation
g. Legislation
h. National adaptation strategy or plan
i. Other organisations' example
j. Growth and new business opportunities
k. Can't say

1. Other, what?

19. What are the two most important drivers of weather and climate risk management in your organization? (Secondary driver)
a. Avoiding economic losses
b. Work safety
c. Process safety
d. Environmental safety
e. Health protection
f. Responsibility and reputation as part of business ac- tivities/activities
g. Legislation
h. National adaptation strategy or plan
i. Example of other organisations
j. Growth and new business opportunities

k. I don't know

1. Other, what?

20. Has your organization experienced any realization significant weather or climate risk? If so, what?
a. No
b. Yes
c. I don't know

21. If you answered "Yes", please choose how the risk was realized. You may choose multiple options.
a. Damage on property
b. Injuries
c. Environmental damage or accident
d. Production disruption or other business disruption
e. Damage on reputation
f. Opening of new business opportunity
g. Other, what?

22. Compared to other risks your organization has to consider weather and climate risks are:
a. Non-existent
b. Small
c. Equally significant
d. Big
e. Extremely big
f. I don't know

23. If you have other thoughts or comments about the effects of weather and climate, you can write them here.

24. Are you aware or did you use the following weather and climate information sources? (Use regularly; Have heard but used randomly; Have heard but not used; Haven't heard or used)
a. http://www.Climateguide.fi
b. Tulvakeskus ("flood center") warnings
c. LUOVA (official natural disaster warning system) releases
d. Long term projections provided by the Finnish Me- teorological Institute
e. Flood maps
f. Open data provided by the research institutes (e.g. weather information, hydrological information)
g. IPCC climate change scenarios
h. Consultants
i. Other, what? 
25. Assess the usefulness of the following data sources for weather and climate risk management. (Very useful; useful; somewhat useful; somewhat useless; useless; detrimental)
a. Internal experts
b. Contacts with external experts
c. Consultants
d. Industry networks and organizations
e. Stakeholder feedback (surveys, interviews, work- shops, public events)
f. Professional literature and experts reports
g. Scientific publications
h. Social media
i. Traditional media
j. Websites dealing with weather and climate issues (e.g. Climateguide.fi; Tulvakeskus)
k. Standards and instructions
1. Tools illustrating climate change or its impacts (e.g. risk or vulnerability calculators, flood maps)
m. Historical data (e.g. heritage, photos and maps)
n. Public spatial data sets
o. Open weather and climate data
p. Other, what

26. Do you gather information on the impact of exceptional weather and climate change on your organization? Is this information available to outsiders?

a. Yes we collect, we share the information partly or entirely openly

b. Yes we collect, we share the information to chosen partners

c. Yes we collect, we don't share the information with outsiders but we would be interested in sharing

d. Yes we collect, we don't share the information to outsiders

e. No we don't collect

f. I don't know

27. If you have other ideas about the sources of information and their usefulness, you can write them here.

28. Below is a list of limiting factors that may hinder weather and climate risk management. Evaluate their significance for your organization. (Very significant, significant, somewhat significant, somewhat meaningless, meaningless)

a. Uncertainties related to climate information b. Spatial and temporal inaccuracy in climate information

c. The information provided is not in a form (for example, in a visualized form or comprehensible language) that supports decision making

d. Networks to the producers of climate information are missing or are poor

e. Lack of trust towards the producers of climate information

f. Limitation of own expertise or technical capacity

g. My own limited financial or temporal resources

h. Unclear division of responsibilities in own organization

i. Incomplete information on the effects of weather and climate on our organization's activities

j. Lack of technical solutions or problems related to technology

k. Unclear division of responsibilities with other organizations

1. Different time horizons between climate risks and organization's own activities

m. Differences in risk perceptions within own organization

n. Differences in risk perceptions between own and other organizations

29. Do you recognize other factors that limit weather and climate risk management?

30. Below is a list of ways to promote weather and climate risk management. Evaluate how important they are for your organization. (Very significant, significant, somewhat significant, somewhat meaningless, meaningless)

a. Increasing cooperation between climate information users and producers

b. Adapting the content of climate information to user needs

c. Improving access to information

d. Improving the usability of information

e. Developing know-how related to weather and climate within own organization

f. Improving the timing and regional distinctiveness of climate information

g. Production of short-term (5 to 10 years) climate scenarios

h. Inclusion of probabilities in forecasts and estimates

i. Sector-specific guides to weather and climate risk management 
j. Other, what?

31. If you have other ideas about developing anticipation and preparedness, you can write them here.

32. If you want to give feedback or say something related to the questionnaire, you can write them here. 
Competing interests. The authors declare that they have no conflict of interest.

Special issue statement. This article is part of the special issue "16th EMS Annual Meeting \& 11th European Conference on Applied Climatology (ECAC)". It is a result of the 16th EMS Annual Meeting \& 11th European Conference on Applied Climatology (ECAC), Trieste, Italy, 12-16 September 2016.

Acknowledgements. The authors wish to thank all the partners who participated in the ELASTINEN project.

Edited by: Irene Fischer-Bruns

Reviewed by: two anonymous referees

\section{References}

Berkhout, F.: Adaptation to climate change by organizations, WIREs Clim. Change, 3, 91-106, https://doi.org/10.1002/wcc.154, 2012.

Bolson, J., Martinez, C., Breuer, N., Srivastava, P., and Knox, P.: Climate information use among southeast US water managers: beyond barriers and toward opportunities, Reg. Environ. Change, 13, 131-151, https://doi.org/10.1007/s10113-013-0463-1, 2013.

Gregow, H., Haavisto, R., Harjanne, A., Luhtala, S., Mäkelä, A., Tuomenvirta, H., Halonen, M., Raivio, T., Hildén, M., Jakkila, J., Parjanne, A., Peltonen-Sainio, P., Kollanus, V., Lanki, T., Miettinen, I., Haanpää, S., Juhola, S., Jurgilevich, A., and Räsänen, A.: FSD3105 Weather and Climate Risk Management in Finnish Organisations 2015, available at: http://urn.fi/urn:nbn:fi: fsd:T-FSD3105, 2015.

Gregow, H., Carter, T., Groundstroem, F., Haavisto, R., Haanpää, S., Halonen, M., Harjanne, A., Hildén, M., Jakkila, J., Juhola, S., Jurgilevich, A., Kokko, A., Kollanus, V., Lanki, T., Luhtala, S., Miettinen, I., Mäkelä, A., Nurmi, V., Oljemark, K., Parjanne, A., Peltonen-Sainio, P., Perrels, A., Pilli-Sihvola, K., Punkka, A.-J., Raivio, T., Räsänen, A., Säntti, K., Tuomenvirta, H., Veijalainen, N., and Zacheus, O.: Measures to promote the management of weather and climate related risks, Publications of the Government's analysis, assessment and research activities 47/2016, Finnish Prime Minister's Office, 2016 (in Finnish).

Guston, D. H.: Stabilizing the boundary between U.S. politics and science: The role of the Office of Technology Transfer as a boundary organization, Soc. Stud. Sci., 29, 87-112, https://doi.org/10.1177/030631299029001004, 1999.

Harjanne, A., Haavisto, R., Tuomenvirta, H., Luhtala, S., Mäkelä, A., Gregow, H., Halonen, M., Raivio, T., Hildén, M., Parjanne, A., Jakkila, J., Juhola, S., Räsänen, A., Haanpää, S., Jurgilevich, A., Peltonen-Sainio, P., Lanki, T., Miettinen, I., Zacheus, O., and Kollanus, V.: Sää- ja ilmastoriskien hallinta ja tietolähteet Suomessa, Finnish Meteorological Institute Reports 2016, 6, 2016 (in Finnish).
Hoppe, R. and Wesselink, A.: Comparing the role of boundary organizations in the governance of climate change in three EU member states, Environ. Sci. Policy, 44, 73-85, https://doi.org/10.1016/j.envsci.2014.07.002, 2014.

Kirchhoff, C. J., Lemos, M. C., and Dessai, S.: Actionable Knowledge for Environmental Decision Making: Broadening the Usability of Climate Science, Annu. Rev. Env. Resour., 38, 393-414, https://doi.org/10.1146/annurev-environ-022112$112828,2013$.

Lash, J. and Wellington, F.: Competitive Advantage on a Warming Planet, Harvard Business Review, March 2007, 95-102, 2007.

Lemos, M. C., Kirchhoff, C. J., and Ramprasad, V.: Narrowing the climate information usability gap, Nature Climate Change, 2, 789-794, 2012.

Linnenluecke, M. K., Griffiths, A., and Winn, M. I.: Firm and industry adaptation to climate change: a review of climate adaptation studies in the business and management field, WIREs Clim. Change, 4, 397-416, https://doi.org/10.1002/wcc.214, 2013.

Lourenço, T. C., Swart, R., Goosen, H., and Street, R.: The rise of demand-driven climate services, Nature Climate Change, 6, 1314, https://doi.org/10.1038/nclimate2836, 2015.

McGregor, G.: Climatology in support of climate risk management: A progress report, Prog. Phys. Geog., 39, 536-553, https://doi.org/10.1177/0309133315578941, 2015.

McNie, E.: Delivering Climate Services: Organizational Strategies and Approaches for Producing Useful Climate-Science Information, Weather, Climate and Society, 5, 14-26, https://doi.org/10.1175/WCAS-D-11-00034.1, 2013.

Pilli-Sihvola, K., van Oort, B., Hanssen-Bauer, I., Ollikainen, M., Rummukainen, M., and Tuomenvirta, H.: Communication and use of climate scenarios for climate change adaptation in Finland, Sweden and Norway, Local Environment, 20, 510-524, https://doi.org/10.1080/13549839.2014.967757, 2014.

Soares, M. B. and Dessai, S.: Barriers and enablers to the use of seasonal climate forecasts amongst organisations in Europe, Climatic Change, 137, 89-103, https://doi.org/10.1007/s10584016-1671-8, 2016.

Vaughan, C. and Dessai, S.: Climate services for society: origins, institutional arrangements, and design elements for an evaluation framework, WIREs Clim. Change, 5, 587-603, https://doi.org/10.1002/wcc.290, 2014.

Winn, M. I., Kirchgeorg, M., Griffi, A., Linnenluecke, M., and Günther, E.: Impacts from Climate Change on Organizations: a Conceptual Foundation, Business Strategy and the Environment, 20, 157-173, https://doi.org/10.1002/bse.679, 2011. 